\title{
Simultaneous portohepatic vein embolization a radiological: a short cut to associating liver partition and portal vein ligation for staged hepatectomy?
}

\author{
Ka Wing Ma, Albert Chi Yan Chan \\ Department of Surgery, Li Ka Shing Faculty of Medicine, the University of Hong Kong, Hong Kong, China \\ Correspondence to: Albert Chi Yan Chan, MS, FACS, FRCS. Division of Hepatobiliary \& Pancreatic Surgery, \& Liver Transplantation, Department \\ of Surgery, Li Ka Shing Faculty of Medicine, The University of Hong Kong, Room 340, Block L, Queen Mary Hospital, 102 Pokfulam Road, Hong \\ Kong, China. Email: acchan@hku.hk. \\ Comment on: Laurent C, Fernandez B, Marichez A, et al. Radiological simultaneous portohepatic vein embolization (RASPE) before major \\ hepatectomy: a better way to optimize liver hypertrophy compared to portal vein embolization. Ann Surg 2020;272:199-205.
}

Submitted Dec 28, 2020. Accepted for publication Jan 20, 2021.

doi: 10.21037/hbsn-20-862

View this article at: http://dx.doi.org/10.21037/hbsn-20-862

Insufficient future liver remnant (FLR) represented one of the most common contraindications for major hepatectomy as post-hepatectomy liver failure (PHLF) was associated with high mortality with no effective treatment. Since the description of portal vein embolization (PVE) by Makucchi in 1984 (1), FLR volumetric modulation was made possible. Use of PVE before major hepatectomy for patients with insufficient FLR (i.e., $<30 \%$ of estimated standard liver volume) had greatly improved resectability, operative as well as survival outcomes of patients with hepatocellular carcinoma (2). This has defined the role of PVE to be the standard approach for patients with insufficient FLR contemplating for major hepatectomy in the past decades. However, the need for 4 to 6 weeks waiting time to allow FLR hypertrophy undermined one of its major shortcomings. In a recent large series of PVE (3), $34 \%$ of the patients who initially had resectable disease was reported to become unresectable. Release of growth factors following embolization and the long waiting time after the procedure imposed a substantial risk of tumour progression, which accounted for the high unresectability rate after PVE. Furthermore, failed PVE and suboptimal FLR hypertrophy constituted another common reason for unresectability with up to $15 \%$ of the cases could not achieve adequate FLR hypertrophy after the procedure (2).

Since 2012, an alternative to PVE namely, associating liver partition and portal vein ligation for staged hepatectomy (ALPPS) started to become popular. The
ALPPS approach was shown to be effective to induce substantial FLR hypertrophy in a much shorter period of time (22.7 vs. 3.8 cc per day) (4). In addition, rapid FLR hypertrophy was accompanied by the corresponding hepatic functional improvement (5). Parenchymal dissociation between FLR and the tumour bearing segment led to complete cut-off of the supply of intestinal trophic hormones to the liver lobe which is to be resected (6), and promote a dramatic volumetric and functional hypertrophy not achievable by PVE. Despite these advantages, ALPPS is often criticised for the increased procedure-related morbidity and mortality (6) in addition to the need for two-stage operation. Till quite recently, a procedure known as radiological simultaneous portohepatic vein embolization (RASPE) has been introduced, by inducing complete "venous deprivation" to induce FLR hypertrophy. Hepatic vein embolization (HVE) was initially developed as a sequential, supplementary procedure to salvage the suboptimal FLR hypertrophy from PVE (7). Considering its relatively low procedural risk (8), HVE and PVE are more frequently performed as a package (i.e., the RASPE) procedure in order to achieve maximal hypertrophy and avoid further delay with the sequential approach. Recently, a matched retrospective comparison between RASPE and PVE was published (9). Disregard the selection bias and small sample size in that study, it clearly demonstrated the superiority of RASPE over PVE alone in terms of the extent of anatomical, functional hypertrophy, compromising 
Table 1 Comparing characteristics of RASPE versus ALPPS

\begin{tabular}{lll}
\hline Characteristics & RASPE & ALPPS \\
\hline Expertise & Interventional radiologist & Hepatobiliary surgeon \\
Mode of anaesthesia & Local infiltration with conscious sedation & General anaesthesia \\
Facilities and equipment & Interventional radiology suite with & Operation theatre capable of supporting major hepatic \\
& ultrasound and fluoroscopy support & surgery \\
Duration of procedure & Short, around 1 hour & Few hours \\
Complication and risk & Low & Up to 20\% \\
Hospital length of stay & $1-2$ days & - \\
Expected percentage of hypertrophy & $>30 \%$ & $>30 \%$ \\
Waiting time for hypertrophy complete & $>4$ weeks & 1 week \\
Bilobar disease & Not suitable & Resection of tumour in FLR during parenchymal split \\
Hilar cholangiocarcinoma & Suitable & Relative contraindication \\
Cost & Could be high related to endovascular & High due to operating theatre cost \\
Oncological outcomes & equipment and emboli materials &
\end{tabular}

ALPPS, associating liver partition and portal vein ligation for staged hepatectomy; RASPE, radiological simultaneous portohepatic vein embolization; FLR, future liver remnant; PVE, portal vein embolization.

patient safety and short-term operative outcomes.

Although RASPE has emerged as an improved version of PVE that could one day become the standard approach for radiological FLR modulation, the impact of RASPE by simultaneously occluding the inflow and outflow vessels in the tumor-bearing liver lobes in diseased liver (i.e., cirrhotic liver, fatty liver, liver after chemotherapy, etc.) remained unclear. Besides, more data is required to define its longterm oncological outcomes in different cancer types. When compared with ALPPS which was FLR modulation by direct surgical means, there are pros and cons (Table 1) with RASPE in its own right. Clinicians should choose according to patient status (performance status), liver status (hepatic function and presence of parenchyma), tumour status (bilaterality and geometry) and availability of expertise. Future studies in a multi-centre prospective manner comparing RASPE and ALPPS would give us more valuable information about their respective roles in hepatectomy for insufficient FLR.

\section{Acknowledgments}

Funding: None.

\section{Footnote}

Provenance and Peer Review: This article was commissioned by the editorial office of Hepatobiliary Surgery and Nutrition. The article did not undergo external peer review.

Conflicts of Interest: Both authors have completed the ICMJE uniform disclosure form (available at https://hbsn. amegroups.com/article/view/10.21037/hbsn-20-862/coif). Dr. ACYC serves as an unpaid editorial board member of $H B S N$. The other author has no conflicts of interest to declare.

Ethical Statement: The authors are accountable for all aspects of the work in ensuring that questions related to the accuracy or integrity of any part of the work are appropriately investigated and resolved.

Open Access Statement: This is an Open Access article distributed in accordance with the Creative Commons Attribution-NonCommercial-NoDerivs 4.0 International License (CC BY-NC-ND 4.0), which permits the noncommercial replication and distribution of the article with 
the strict proviso that no changes or edits are made and the original work is properly cited (including links to both the formal publication through the relevant DOI and the license). See: https://creativecommons.org/licenses/by-nc-nd/4.0/.

\section{References}

1. Makuuchi M, Thai BL, Takayasu K, et al. Preoperative portal embolization to increase safety of major hepatectomy for hilar bile duct carcinoma: a preliminary report. Surgery 1990;107:521-7.

2. Alvarez FA, Castaing D, Figueroa R, et al. Natural history of portal vein embolization before liver resection: a 23-year analysis of intention-to-treat results. Surgery 2018;163:1257-63.

3. Shindoh J, Tzeng CW, Aloia TA, et al. Portal vein embolization improves rate of resection of extensive colorectal liver metastases without worsening survival. $\mathrm{Br} \mathrm{J}$ Surg 2013;100:1777-83.

4. Chan A, Zhang WY, Chok K, et al. ALPPS Versus Portal Vein Embolization for Hepatitis-related Hepatocellular Carcinoma: A Changing Paradigm in Modulation of Future Liver Remnant Before Major Hepatectomy. Ann Surg 2021;273:957-65.

Cite this article as: Ma KW, Chan ACY. Simultaneous portohepatic vein embolization a radiological: a short cut to associating liver partition and portal vein ligation for staged hepatectomy? HepatoBiliary Surg Nutr 2021;10(3):373-375. doi: 10.21037/hbsn-20-862
5. Serenari M, Collaud C, Alvarez FA, et al. Interstage Assessment of Remnant Liver Function in ALPPS Using Hepatobiliary Scintigraphy: Prediction of Posthepatectomy Liver Failure and Introduction of the HIBA Index. Ann Surg 2018;267:1141-7.

6. Cai YL, Song PP, Tang W, et al. An updated systematic review of the evolution of ALPPS and evaluation of its advantages and disadvantages in accordance with current evidence. Medicine (Baltimore) 2016;95:e3941.

7. Hwang S, Lee SG, Ko GY, et al. Sequential preoperative ipsilateral hepatic vein embolization after portal vein embolization to induce further liver regeneration in patients with hepatobiliary malignancy. Ann Surg 2009;249:608-16.

8. Guiu B, Chevallier P, Denys A, et al. Simultaneous transhepatic portal and hepatic vein embolization before major hepatectomy: the liver venous deprivation technique. Eur Radiol 2016;26:4259-67.

9. Laurent C, Fernandez B, Marichez A, et al. Radiological Simultaneous Portohepatic Vein Embolization (RASPE) Before Major Hepatectomy: A Better Way to Optimize Liver Hypertrophy Compared to Portal Vein Embolization. Ann Surg 2020;272:199-205. 